\title{
PEMBERIAN ASI BERPENGARUH TERHADAP RESPON NYERI BAYI PADA PENYUNTIKAN IMUNISASI PENTAVALEN
}

\author{
Atikah,Kosma Heryati, Eliana, \\ Politeknik Kesehatan Kementrian Kesehatan Bengkulu, Jurusan Kebidanan \\ Atikah.abay@gmail.com
}

\begin{abstract}
Immunization in infants is an action that can lead to trauma because it can cause pain. One of the techniques of non-pharmacological pain management is by breastfeeding. The purpose of this study was to determine the effect of Breastfeeding on pain reduction in infants immunization Pentavalen.The study uses Quasy experimental methods with static group comparation and sampling techniques using consecutive sampling, the number of samples obtained 54 respondents. This study conducted in In Health Center Sawah Lebar Bengkulu City at the date of 11 September - 10 October 2017. Analysis of pain response using the Independent Sample t-Test. The results showed the average level of pain in infants the intervention group is 3,89. Whereas in the control group the average pain level was 7.63. Results of bivariat analysis there is a difference the average level of pain in breastfed infants (intervention) compared with infants given touch terapy (control) at the time of immunization Pentavalen injections amount 3,74 $(p=0,000)$. Expected for Health Center especially immunization officer can apply management of reduction non-pharmacological in infant who performed immunization injection that is Breastfeeding intervetion before and after at the time of immunization injections which is one Baby's Care.
\end{abstract}

Keywords : Breastfeeding, Infant Pain Respon

\begin{abstract}
Abstrak:Imunisasi pada bayi merupakan tindakan yang dapat menimbulkan trauma karena hal tersebut dapat menyebabkan nyeri. Salah satu teknik menejemen nyeri nonfarmakologi adalah dengan pemberian ASI. Tujuan dari penelitian ini adalah untuk mengetahui efektifitas pemberian ASI terhadap penurunan respon nyeri pada bayi yang dilakukan imunisasi Pentavalen. Penelitian menggunakan metode Quasi Eksperimen dengan static group comparationdan teknik pengambilan sampel menggunakan consecutive sampling, jumlah sampel didapatkan 54 responden. Penelitian ini dilakukan di Puskesmas Sawah Lebar Kota Bengkulu pada tanggal 11 September - 10 Oktober 2017. Analisis perbedaan respon nyeri menggunakan Independent Sample t-Test. Hasil penelitian ini menunjukkan rata-rata respon nyeri pada bayi pada kelompok intervensi adalah 3,89. Sedangkan pada kelompok kontrol rata-rata tingkat nyerinya adalah 7.63. Hasil analisis bivariat menunjukkan ada perbedaan rata-rata respon nyeri pada bayi yang diberikan ASI (intervensi) dengan bayi yang diberikan terapi sentuhan (kontrol) pada saat dilakukan penyuntikan imunisasi Pentavalen sebesar 3,74 $(p=0,000)$. Diharapkan bagi Puskesmas khususnya petugas imunisasi dapat menerapkan prinsip menurunkan respon nyeri pada bayi yang diimunisasi yaitu dengan melakukan intervensi pemberian ASI sebelum dan sesudah dilakukan penyuntikkan imunisasi pada bayi yang merupakan salah satu Asuhan Sayang Bayi.
\end{abstract}

Kata Kunci : Pemberian ASI, Respon Nyeri Bayi

Anak merupakan generasi penerus yang menentukan masa depan suatu bangsa di masa yang akan datang. Tujuan tersebut harus didukung dengan pembangunan di segala aspek kehidupan, diantaranya pendidikan, ekonomi, sosial dan kesehatan. Pembangunan kesehatan merupakan salah satu bagian dari pembangunan nasional yang diupayakan oleh pemerintah dalam meningkatkan 
kualitas sumber daya manusia. Salah satu sasaran utama pembangunan kesehatan adalah anak-anak, terutama pada usia bayi (Anggraini J, 2015).

Periode bayi merupakan rentang usia anak 0-12 bulan. Mekanisme penting yang harus didapatkan oleh bayi pada awal kehidupannya adalah imunitas terhadap berbagai penyakit. Sistem imunitas pada masa bayi sama dengan orang dewasa, tetapi belum berkembang dengan sempurna pada saat lahir (Anggraini J, 2015). Hal inilah yang menyebabkan bayi rentan terhadap infeksi berbagai penyakit. Kesakitan dan kematian bayi ini dapat menjadi indikator dalam menentukan derajat kesehatan (Rahayuningsih SI, 2012).

Setiap tahun lebih dari 1,4 juta anak di dunia meninggal karena berbagai penyakit yang sebenarnya dapat dicegah dengan imunisasi. Upaya preventif dikembangkan pemerintah melalui penerapan wajib imunisasi dasar pada satu tahun pertama kehidupan anak. Keberhasilan seorang bayi dalam mendapatkan imunisasi dasar tersebut diukur melalui indikator imunisasi dasar lengkap (Kementrian Kesehatan RI, 2016).

Cakupan imunisasi dasar lengkap di kota bengkulu pada tahun 2016 terendah yaitu puskesmas Sawah Lebar 81,6\%, dari jumlah sasaran 415 bayi, yang mendapatkan imunisasi 343 bayi, artinya ada angka Drop Out imunisasi sebesar $17,3 \%$ atau 72 bayi yang tidak mendapatkan imunisasi dasar lengkap (Dinkes Kota Bengkulu, 2016). Berdasarkan wawancara dengan bidan Puskesmas Sawah Lebar Tanggal 9 Juni 2017 penyebab langsung Drop Out imunisasi antara lain karena orang tua takut terjadinya Kejadian Ikutan Pasca Imunisasi (KIPI) seperti demam, nyeri dan bengkak. Angka kejadian bengkak bayi saat imunisasi diperkirakan 2:10 bayi yang diimunisasi.

Pemberian imunisasi dengan prosedur injeksi dapat menimbulkan nyeri pada bayi. Nyeri akibat injeksi merupakan nyeri yang dirasakan pada anak sebagai pengalaman sensorik dan emosional yang tidak menyenangkan akibat dari kerusakan jaringan yang aktual dan potensial. (Anggraini J, 2015). Menurut teori perkembangan psikoseksual, usia bayi (012 bulan) masuk dalam fase oral, dimana bayi mendapat kepuasan melalui rangsangan ataupun stimulus yang berpusat pada mulut. Strategi penurunan nyeri dengan menggunakan tekhnik pemberian ASI merupakan penatalaksanaan nyeri non farmakologi (Putra I.B, 2014).

Asupan gula maupun larutan manis dapat mengurangi rasa sakit, seperti rasa manis yang terdapat pada ASI. Hal ini dikarenakan oleh pelepasan Betha 
endorphin (horman opiat endrogen, yang diproduksi sendiri oleh tubuh, sifatnya mirip dengan morfin) dan mekanisme preabsorbsi dari rasa manis. Betha endorphin dihasilkan oleh fetus pada saat lahir oleh glandula pituitary hypothalamus, yang berikatan dengan reseptor di otak, serta mengatur regulasi perasaaan nyeri. Ketika ibu memberikan ASI pada anaknya, maka akan menumbuhkan ikatan psikologis antara ibu dan bayi. Proses ini disebut "perlekatan" (bounding). Bayi pun menjadi jarang menangis dan rewel (Anggraini J, 2015).

Hasil penelitian yang dilakukan oleh Kurniawan, Arief Dharma (2013). bahwa rata-rata tingkat nyeri pada bayi yang diberikan ASI (intervensi) lebih rendah dibandingkan dengan bayi yang tidak diberikan ASI (kontrol) pada saat dilakukan penyuntikan imunisasi $(p=0.000)$. Menurut Rahayuningsih, Sri Intan (2012) dalam penelitiannya bahwa bayi yang disuntik imunisasi Combo memiliki tingkat nyeri paling tinggi. Karena adanya perbedaan ukuran jarum yang digunakan lebih besar dan volume vaksin yang lebih banyak.

Berdasarkan studi pendahuluan di Puskesmas Sawah Lebar pada tanggal 9 Juni $2017 \quad 10$ bayi yang diberikan imunisasi di Posyandu, ternyata terdapat 9 atau $90 \%$ bayi menunjukkan respon nyeri menagis, dan 1 atau $10 \%$ bayi tidak menunjukkan respon nyeri yang dialaminya terlihat dari tangisan atau rengekan bayi yang lama serta sulit untuk didiamkan, respon memberontak dengan menendang atau menginjak kaki dengan menyentak, wajah meringis. Namun, belum ada penanganan terhadap nyeri tersebut, penatalaksanaan yang dilakukan hanya untuk mengatasi Kejadian Ikutan Pasca-Imunisasi (KIPI) akibat reaksi vaksin, seperti demam dan bengkak.

\section{BAHAN DAN CARA KERJA.}

Metode dalam penelitian ini adalah penelitian kuantitatif, menggunakan desain penelitian Quasi Eksperimen dengan static group comparation. Variabel dalam penelitian ini adalah variabel independen (pemberian ASI dan pemberian terapi sentuhan) dan variabel dependen (respon nyeri bayi). Serta variabel luar dalam penelitian ini adalah jenis kelamin, umur dan berat badan bayi.

Sampel penelitian ini berjumlah 54 bayi yang diambil dengan rumus Lemeshow. Metode pengambilan sampel dalam penelitian ini adalah non probability sampling sejenis consecutive sampling. Kriteria inklusi: Bersedia menjadi responden, usia bayi antara 2-6 bulan, bayi minum ASI, menerima imunisasi Pentavalen (DPT/HB-HiB). Kriteria ekskulsi: bayi sakit dan mengalami kontraindikasi untuk imunisasi 
Instrumen dalam penelitian ini adalah kuesioner karakteristik dan lembar observasi skala nyeri FLACC. Teknik pengumpulan data adalah data primer yang diperoleh langsung dari responden. Pengumpulan data dilakukan dengan mengambil data primer yaitu karakteristik (umur, berat badan bayi dan jenis kelamin), respon nyeri bayi saat penyuntikkan imunisasi pentavalen pada kelompok intervensi pemberian ASI dan kelompok kontrol terapi sentuhandengan menggunakan lembar observasi skala nyeri FLACC. Penelitian ini menggunakan analisis univariat, analisis bivariat (uji Independent Sample T-test) dan analisis multivariat Uji Ancova.

\section{HASIL}

\section{Analisis Univariat}

Tabel 1. Distribusi Frekuensi jenis kelamin bayi di Puskesmas Sawah Lebar Tahun 2017

\begin{tabular}{ccc}
\hline Karakteristik & $\begin{array}{c}\text { Frekuensi (F) } \\
\mathbf{n = 5 4}\end{array}$ & $\begin{array}{c}\text { Presentase } \\
(\mathbf{\%})\end{array}$ \\
\hline Laki-laki & 20 & 37 \\
perempuan & 34 & 63 \\
\hline
\end{tabular}

Berdasarkan tabel 1 diatas dapat dilihat bahwa sebagian besar bayi dengan jenis kelamin perempuan $(63 \%)$.

Tabel 2. Distribusi Frekuensi Umur dan Berat Badan bayi di Puskesmas Sawah Lebar Tahun 2017

\begin{tabular}{lcccc}
\hline $\begin{array}{c}\text { Karakteris } \\
\text { tik }\end{array}$ & Mean & $\begin{array}{c}\text { Std. } \\
\text { Deviasi }\end{array}$ & Min & Max \\
\hline Umur & 3,515 & 1,225 & 2,00 & 6,00 \\
Berat & 6,342 & 1,290 & 3,60 & 8,80 \\
Badan Bayi & & & & \\
\hline
\end{tabular}

$\overline{\text { Berdasarkan tabel } 2 \text { di atas dapat dilihat bahwa }}$ rata-rata umur bayi 3,5 bulan dengan Berat Badan bayi 6.342 gram.

\section{Respon Nyeri Bayi pada Penyuntikkan Imunisasi Pentavalen}

Tabel 3. Rata-Rata Respon Nyeri Bayi pada Penyuntikkan Imunisasi Pentavalen pada Kelompok Intervensi dan Kelompok Kontrol

\begin{tabular}{ccccc}
\hline Variabel & $\boldsymbol{N}$ & Mean & SD & $\begin{array}{c}\text { Min- } \\
\text { Max }\end{array}$ \\
\hline Intervensi & 27 & 3,89 & 1,281 & $2-7$ \\
Kontrol & 27 & 7,63 & 1,445 & $5-10$ \\
\hline
\end{tabular}

Berdasarkan tabel 3 di atas, dapat disimpulkan bahwa rata-rata respon nyeri pada kelompok intervensi adalah 3,89 dan rata-rata respon nyeri pada kelompok kontrol adalah 7,63.

\section{Analisis Bivariat}

Tabel 4. Efektivitas Pemberian ASI terhadap Respon Nyeri Bayi pada Penyuntikkan Imunisasi Pentavalen di Puskesmas Sawah Lebar Tahun 2017

\begin{tabular}{cccccc}
\hline Variabel & $\mathbf{N}$ & Mean & $\begin{array}{c}\sum_{\text {Mean }} \\
\text { SD }\end{array}$ & $\begin{array}{c}\boldsymbol{p} \\
\text { value }\end{array}$ \\
\hline Intervensi & 27 & 3,89 & 3,74 & 1,281 & 0,000 \\
Kontrol & 27 & 7,63 & & 1,445 & \\
\hline
\end{tabular}

Berdasarkan tabel 4 di atas, dapat disimpulkan bahwa terdapat perbedaan rata-rata respon nyeri bayi pada kelompok intervensi dan kontrol sebesar 3,74 dengan $p$ value $=0,000$.

Tabel 5. Analisis Pengaruh Berat Badan, Umur dan Jenis Kelamin terhadap Respon Nyeri Bayi pada Penyuntikkan Imunisasi Pentavalen di Puskesmas Sawah Lebar Tahun 2017

\begin{tabular}{cc}
\hline Variabel & P value \\
\hline Berat badan & 0,240 \\
Umur & 0,186 \\
Jenis kelamin & 0,225 \\
\hline
\end{tabular}

Berdasarkan tabel 5, analisis pengaruh berat badan, jenis kelamin dan umur dengan uji korelasi regresi dan independent t-tes, dapat disimpulkan hasil $p$ value dari masingmasing variabel $<0,25$. Jadi semua variabel menjadi kandidat dalam analisis multivariat. 


\section{Analisis Multivariat}

Analisis multivariat ini digunakan untuk mengetahui variabel lain yang mempengaruhi respon nyeri bayi saat penyuntikkan imunisasi. Uji yang digunakan adalah analisis kovarian (Ancova) dengan menggunakan model Type III Sum of Square. Hasil analisis digambarkan pada tabel 6 berikut :

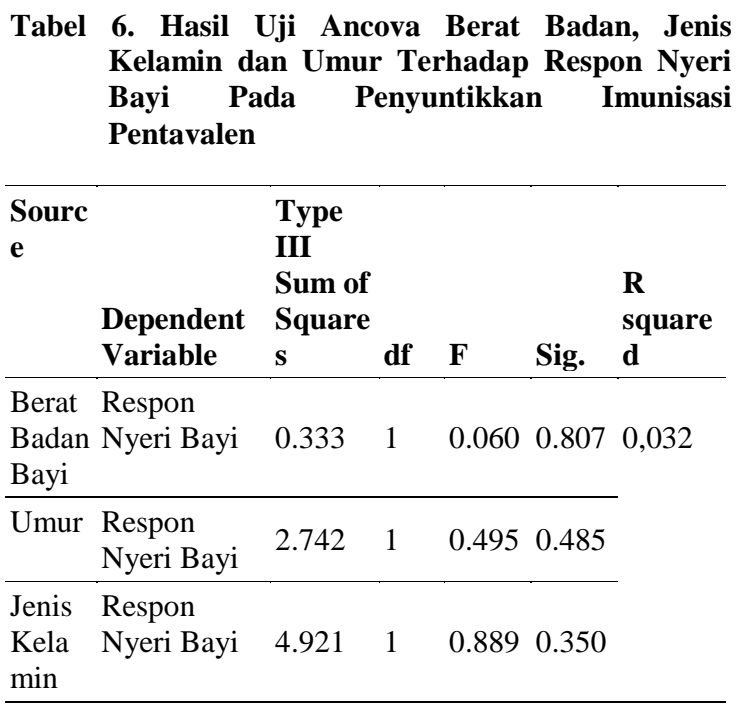

Dari tabel 6 di atas menunjukkan bahwa variabel berat badan bayi, jenis kelamin dan umur bukan merupakan faktor yang mempengaruhi nyeri pada bayi saat penyuntikkan imunisasi Pentavalen dengan $p>0,05$ dan hanya memberikan kontribusi pengaruh sebesar $3,2 \%$ terhadap respon nyeri bayi.

\section{PEMBAHASAN}

Hasil penelitian menunujukkan bahwa ada perbedaan rata-rata respon nyeri bayi pada kelompok intervensi pemberian ASI dengan kelompok kontrol yang diberikan terapi sentuhan saat penyuntikkan imunisasi pentavalen di Puskesmas Sawah Lebar Tahun 2017 sebesar 3,74 dengan $p$ value $=0,000$. Dapat disimpulkan, pemberian ASI efektif dalam menurunkan respon nyeri bayi saat penyuntikkan imunisasi Pentavalen.

\section{Efektifitas Pemberian ASI terhadap Respon Nyeri Bayi}

Berdasarkan tabel 4 pada kelompok yang diberikan ASI menunjukkan bahwa ratarata respon nyeri bayi yang di ukur dengan skala nyeri FLACC adalah 3,86 dengan standar defiasi 1,281 dengan nilai $p=0.000$, dapat disimpulkan pemberian ASI efektif menurunkan respon nyeri bayi yang diberikan imunisasi.

Penelitian yang dilakukan ini dapat menguatkan teori yang sudah ada bahwa pemberian ASI sebelum dilakukan penyuntikkan imunisasi Pentavalen dapat mengurangi nyeri pada saat imunisasi dilakukan. MenurutWulandari menyusuidapatmenguranginyeridanmenenang kanbayidenganadanyakontakkulit yang bisamengalihkanperhatianbayi.Kandungangula pada ASI memilikiefek yang dapatmenghilangkan rasa sakit.Menurutpakar, jikapenatalaksanaantersebutdilakukandenganb enar, bayiakanberhentimenangisdalam 45 detiksetelahimunisasi.

Asupan gula maupun larutan manis dapat mengurangi rasa sakit, seperti rasa manis yang terdapat pada ASI. Hal ini dikarenakan oleh pelepasan Betha endorphin (horman opiat endrogen, yang diproduksi sendiri oleh tubuh, sifatnya mirip dengan morfin) dan mekanisme preabsorbsi dari rasa manis. Betha endorphin dihasilkan oleh fetus pada saat lahir oleh glandula pituitary hypothalamus, yang berikatan dengan reseptor di otak, serta mengatur regulasi perasaaan nyeri. Ketika ibu 
memberikan ASI pada anaknya, maka akan menumbuhkan ikatan psikologis antara ibu dan bayi. Proses ini disebut "perlekatan" (bounding). Bayi pun menjadi jarang menangis dan rewel (Anggraini J, 2015).

Berdasarkan hasil penelitian dan teori di atas dapat disimpulkan bahwa pemberian ASI memegang peranan penting dalam pemberian asuhan kebidanan yang dapat membantu mengatasi rasa nyeri, menimbulkan rasa nyaman, dan mengurangi stres pada bayi. Untuk mewujudkan terlaksananya intervensi pemberian ASI, diperlukan adanya kerja sama dan kesadaran yang tinggi dari bidan dan ibu si bayi. Kemampuan ibu dalam menerapkan pemberian ASI/menyusui untuk mengurangi nyeri saat prosedur imunisasi tidak dapat dipisahkan dari pengetahuan ibu. Oleh karena itu, bidan harus mampu menerapkan cara meminimalkan nyeri pada bayi saat diimunisasi, tidak hanya melakukan penatalaksanaan untuk mengatasi Kejadian Ikutan Pasca-Imunisasi (KIPI) akibat reaksi vaksin, seperti demam dan bengkak.

\section{Efektifitas Terapi Sentuhan terhadap Respon Nyeri Bayi}

Berdasarkan tabel 4 pada kelompok yang diberikan terapi sentuhan menunjukkan bahwa rata-rata respon nyeri bayi adalah 7,63 dengan standar defiasi 1445 . Sedangkan ratarata respon nyeri bayi pada kelompok intervensi lebih rendah sebesar 3,89, jadi dapat disimpulkan pemberian ASI lebih efektif dalam menurunkan respon nyeri daripada pemberian terapi sentuhan.

Sentuhan juga akan merangsang peredaran darah dan akan menambah energi karena gelombang oksigen yang segar akan lebih banyak dikirim ke otak dan ke seluruh tubuh. Namun dibalik ketidak berdayaannya tersebut pada dirinya terdapat berbagai potensi yang siap berkembangan. Bayi akan berkembang dengan baik dan berbagai potensi yang dimiliki dapat berubah menjadi kemampuan nyata bila dirinya mendapatkan stimuli dari lingkungannya, terutama lingkungan sosial. Keluarga merupakan lingkungan pertama dan utama bagi bayi (Ethycasari, 2012).

Hal tersebut menunjukkan hasil yang sama dengan penelitian Ethycasari (2012) dengan judul Perbandingan Efektifitas Antara Metode Bounding (Dekapan) dan Stimulus Kutaneus dalam Mengurangi Rasa Nyeri Suntikan Intramuskuler Pada Bayi. Dari hasil penelitiannya menunjukan adanya perbedaan rata-rata respon nyeri pada kelompok bounding $(2,60)$ dengan respon nyeri pada kelompok stimulasi kutaneus $(7,53)$ dengan $\mathrm{p}=$ 0,000. Artinya, secara psikologis bounding lebih membuat bayi cenderung lebih cepat tenang, nyaman dan merasa mendapatkan kasih sayang sehingga hasil yang didapat bounding terlihat lebih efektif dibanding stimulasi kutaneus, sedangkan stimulasi kutaneus cenderung kurang adanya pendekatan secara psikologis meskipun sama-sama dilakukan dengan sentuhan kulit atau kontak kulit, stimulasi kutaneus hanya usapan dipaha, hal ini yang membedakan bounding lebih efektif karena adanya faktor psikologis antara ibu dan si bayi.

Berdasarkan hasil penelitian dan teori di atas dapat disimpulkan bahwa pemberian 
terapi sentuhan sebelum dan sesudah prosedur imunisasi bukan salah satu asuhan kebidanan yang efektif dalam menurunkan respon nyeri bayi, ada intervensi lain yang lebih efektif yaitu dengan pemberian ASI, karena saat ibu memberikan ASI/menyusui bayinya, akan menumbuhkan ikatan psikologis antara ibu dan bayi. Proses ini disebut "perlekatan" (bounding). Bayi pun menjadi jarang menangis dan rewel (Anggraini J, 2015)

\section{Perbedaan Respon Nyeri Bayi pada Kelompok Intervensi Pemberian ASI dan Kelompok Kontrol Terapi Sentuhan}

Hasil penelitian menunujukkan ada perbedaan rata-rata respon nyeri bayi pada kelompok intervensi pemberian ASI dengan kelompok kontrol yang diberikan terapi sentuhan saat penyuntikkan imunisasi pentavalen di Puskesmas Sawah Lebar Tahun 2017 sebesar 3,74 dengan $p$ value $=$ 0,000.Rata-rata respon nyeri bayi pada kelompok intervensi pemberian ASI sebesar 3,89 yang dikategorikan dalam nyeri ringan.

Dan rata-rata respon nyeri pada kelompok kontrol terapi sentuhan sebesar 7,63 yang dikategorikan dalam nyeri berat. Sesuasi dengan teori Merkel, Voepel-Lewis,Shayevitz, et al,1997 dalam Glasper \& Richardson, 2006; Potts \& Mandleco, 2007 tentang hasil skor perilaku pada skala nyeri FLACC adalah 0: untuk rileks dan nyaman, 1-3: nyeri ringan/ ketidaknyamanan ringan, 4-6 :nyeri sedang, 710: nyeri berat/ ketidaknyamanan berat (Anggraini J, 2015).

Perbedaan rata-rata respon nyeri bayi pada kelompok intervensi pemberian ASI dan kelompok kontrol terapi sentuhan sebesar
3,74 , perbedaan rata-rata respon nyeri ini masuk dalam kategori nyeri ringan, sehingga dapat disimpulkan intervensi pemberian ASI saat prosedur imunisasi pentavalen, dapat menurunkan respon nyeri bayi menjadi nyeri ringan. Karena saat pemberian ASI terjadi pelepasan Betha endorphin (horman opiat endrogen, yang diproduksi sendiri oleh tubuh, sifatnya mirip dengan morfin) dan mekanisme preabsorbsi dari rasa manis. Betha endorphin dihasilkan oleh fetus pada saat lahir oleh glandula pituitary hypothalamus, yang berikatan dengan reseptor di otak, serta mengatur regulasi perasaaan nyeri.

Waktu ibu memberikan ASI pada anaknya, maka akan menumbuhkan ikatan psikologis antara ibu dan bayi. Proses ini disebut "perlekatan" (bounding). Bayi pun menjadi jarang menangis dan rewel (Anggraini J, 2015). Sedangkan terapi sentuhan cenderung kurang adanya pendekatan secara psikologis meskipun sama-sama dilakukan dengan sentuhan kulit atau kontak kulit, terapi sentuhan hanya usapan dipaha sampai pergelangan kaki, hal ini yang membedakan bounding lebih efektif karena adanya faktor psikologis antara ibu dan si bayi.

Berdasarkan pengamatan peneliti dilapangan, perbedaan respon nyeri bayi pada kelompok intervensi pemberian ASI dengan kelompok kontrol terapi sentuhan adalah pada kelompok intervensi setelah dilakukan penyuntikkan imunisasi Pentavalen dilakukan pengukuran respon nyeri bayi, kemudian diberikan ASI kembali, dimana pada umumnya jika bayi diberikan ASI atau bayi menyusu ke ibu, bayi akan berhenti menangis 
dan menikmati kegiatan menyusui yang dapat membuat bayi kenyang sehingga bayi tidak rewel. Sedangkan pada kelompok terapi sentuhan setelah bayi di suntik imunisasi Pentavaelen dan dilakukan pengukuran respon nyeri kemudian diberikan terapi sentuhan kembali, dimana pmberian terapi sentuhan yang hanya dilakukan pada area paha sampai pergelangan kaki kurang adanya pendekatan psikologis antara ibu dan bayi, dan tidak ada sesuatu yang dimasukkan ke dalam mulut seperti kegiatan menyusui yang berdasarkan teori perkembangan psikoseksual, usia bayi (012 bulan) masuk dalam fase oral, dimana bayi mendapat kepuasan melalui rangsangan ataupun stimulus yang berpusat pada mulut.

\section{Pengaruh Berat Badan Bayi, Umur dan Jenis Kelamin terhadap Respon Nyeri Bayi}

Berdasarkan hasil analisis multivariat dengan uji Ancova, hasil analisis variabel berat badan bayi menunjukkan bahwa tidak ada hubungan antara berat badan bayi dengan respon nyeri bayi saat penyuntikan imunisasi $(p=0,800)$. Hal ini menjelaskan bahwa intervensi pemberian ASI efektif menurunkan respon nyeri saat penyuntikan imunisasi bagi berbagai berat badan bayi.

Hal tersebut menunjukkan hasil yang sama dengan penelitian Rahayuningsih, Sri Intan (2012). Hasil penelitian menunujukkan bahwa tidak ada hubungan antara status nutrisi dengan tingkat nyeri bayi saat penyuntikkan imunisasi $(p=1.000)$, proporsi bayi dengan status nutrisi normal yang merasakan nyeri ringan lebih besar daripada bayi yang kurus. Namun hasil analisis bivariat menunjukkan bahwa perbedaan tingkat nyeri tidak ditentukan oleh perbedaan status nutrisi bayi. Berbeda dengan hasil pengamatan dilapangan bahwa bayi dengan berat badan kurus saat dilakukan penyuntikkan imunisasi cenderung menangisnya lebih lama, ini bisa disebabkan karena pada bayi kurus lemak pada area paha lebih tipis daripada bayi dengan berat badan lebih, sehingga saat dilakukan penyuntikkan lebih terasa.

Hasil analisis variabel umur bayi, menunjukkan bahwa tidak ada hubungan antara umur dengan respon nyeri bayi saat penyuntikkan imunisasi $(p=0,485)$. Oleh karena itu, intervensi pemberian ASI efektif menurunkan respon nyeri bayi saat penyuntikkan imunisasi berbagai tingkat umur bayi sampai berusia 6 bulan. Hal tersebut menunjukkan hasil yang sama dengan penelitian Rahayuningsih, Sri Intan (2012). Hasil penelitian memperlihatkan bahwa tidak ada hubungan antara umur dengan tingkat nyeri bayi saat penyuntikkan imunisasi $(p=0,397)$.

Teori yang dikemukakan Bromme et al 1990 bahwa tingkat perkembangan anak akan mempengaruhi proses kognitif dalam mempersepsikan rasa nyeri yang dirasakan anak. Tingkat perkembangan akan sejalan dengan pertambahan usia, sehingga semakin meningkat usia maka toleransi terhadap nyeri pun akan meningkat. Perbedaan hasil analisis dengan teori yang ada dapat disebabkan karena pada usia bayi kemampuan mengontrol nyeri belum berkembang secara sempurna (Rahayuningsih, 2012). Menurut Bowden et al 1998 anak yang belajar teknik mengontrol nyeri akan mampu meminimalisir persepsi 
mereka terhadap nyeri dan perasaan dapat mengontrol situasi. Pada bayi memori terhadap kejadian yang menyakitkan mulai ada pada bayi mencapai usia 6 bulan, meskipun ingatan ini memungkinkan terdapat pada bayi berusia dibawah 6 bulan (Rahayuningsih, 2012).

Ismanto (2011) berpendapat bahwa umur merupakan variabel yang penting dalam mempengaruhi nyeri pada individu. Anak yang masih kecil mempunyai kesulitan dalam memahami nyeri dan prosedur yang dapat menyebabkan nyeri. Anak kecil belum dapat mengucapkan kata-kata juga mengalamai kesulitan dalam mengungkapkan secara verbal. Tingkat perkembangan akan sejalan dengan pertambahan usia, sehingga semakin meningkat usia maka toleransi terhadap nyeri pun meningkat. Hasil pengamatan dilapangan sama dengan hasil statistik, bahwa semua jenis umur bayi tidak mempengaruhi respon nyeri, karena sampel penelitian ini hanya rentang 2-6 bulan saja, sedangkan memori terhadap kejadian yang mneyakitkan mulai ada pada bayi mencapai 6 bulan.

Hasil analisis variabel jenis kelamin, menunjukkan bahwa tidak ada hubungan antara jenis kelamin dan respon nyeri bayi saat penyuntikkan imunisasi $(\mathrm{p}=0,350)$. Hal ini menunujukkan bahwa intervensi pemberian

\section{DAFTAR RUJUKAN}

Anggraini, J, 2015. Pengaruh Pemberian Asi Dan Distraksi Mainan Bersuara Terhadap Skala Nyeri Bayi Yang Mendapat Imunisasi Di Wilayah Kerja Puskesmas Simpang Timbangan Inderalaya.Fakultas

Kedokteran, Universitas Sriwijaya.
ASI efektif menurunkan respon nyeri bayi saat penyuntikkan imunisasi baik pada bayi lakilaki ataupun bayi perempuan. Hal tersebut menunjukkan hasil yang sama dengan penelitian Rahayuningsih, Sri Intan (2012) bahwa tidak ada hubungan antara jenis kelamin dengan tingkat nyeri bayi saat penyuntikkan imunisasi $(p=0,547)$.

\section{KESIMPULAN}

Ada perbedaan rata-rata respon nyeri saat penyuntikkan imunisasi Pentavalen pada kelompok intervensi pemberian ASI dan kelompok kontrol terapi sentuhan sebesar 3,74 dengan $p=0,000$.

Bagi peneliti lain untuk dapat melakukan penelitian dengan intervensi lain seperti pemberian larutan sukrosa yang dapat menurunkan respon nyeri bayi saat penyuntikkan imunisasi Pentavalen.

Bagi bidan pelaksana penelitian ini dapat membantu bidan dan petugas imunisasi di puskesmas agar dapat menerapkan prinsip menurunkan respon nyeri pada bayi yang diimunisasi yaitu dengan melakukan intervensi pemberian ASI sebelum dan sesudah dilakukan penyuntikkan imunisasi pada bayi yang merupakan salah satu Asuhan Sayang Bayi.

Dinas Kesehatan Provinsi Bengkulu. 2015. Profil Kesehatan Provinsi Bengkulu Tahun 2016. Bengkulu : Dinas Kesehatan Kota Bengkulu

Dinas Kesehatan Kota Bengkulu. 2015. Profil Kesehatan Provinsi Bengkulu Tahun 2016. Bengkulu : Dinas Kesehatan Provinsi Bengkulu

. 2016. Profil Kesehatan Provinsi Bengkulu Tahun 2016. Bengkulu : Dinas Kesehatan Provinsi Bengkulu

Ethycasari, 2012. Perbandingan Efektifitas Antara Metode Bounding (Dekapan) Dan Stimulus 
Kutaneus Dalam Mengurangi Rasa Nyeri Suntikan Intramuskuler Pada Bayi. Akper William Booth Surabaya

Ismanto. 2011. Studi Komparatif Pemberian ASI dan Topikal Anastesi terhadap Respon Nyeri Imunisasi pada Bayi di Puskesmas Bahu Manado. Fakultas Ilmu Keperawatan Depok

Kementrian Kesehatan RI. 2015. Profil Kesehatan Indonesia Tahun 2014. Jakarta: Kementerian Kesehatan RI. 2015

. 2016. Profil Kesehatan Indonesia Tahun 2015. Jakarta : Kementerian Kesehatan RI. 2016

Kurniawan, A.D. 2013. Pengaruh Breastfeeding Terhadap Penurunan Nyeri Pada Bayi Yang Dilakukan Imunisasi Di Puskesmas Kasihan 2 Yogyakarta. Fakultas Kedokteran: Universitas Muhammadiyah Yogyakarta.
Putra, I.B. 2014. Pengaruh Family Triple Support (FTS) Berbasis Atraumatic Care terhadap Respon Nyeri Bayi saat Imunisasi Di Puskesmas I Denpasar Barat 2014). Prodi IK. UN Undayana.

Rahayuningsih, S.I., 2012. Efek Pemberian Asi Terhadap Tingkat Nyeri Bayi Saat Penyuntikan Imunisasi Di Kota Depok. Idea Nursing Journal, Vol. III No. 2 2012. Ilmu Keperawatan Maternal : Universitas Syiah Kuala, Banda Aceh.

Wulandari. 2013.5s cara menenangkan bayi setelah imunisasi.https://www.ibudanbalita.com/for um/diskusi/5s-cara-menenangkan-bayisetelah-imunisasi. diunduh pada tanggal 11 Oktober 2017 jam 20.00 WIB. 